\title{
Examining the Problem Frequency and Criticality Rate of an Online Health Sensitization Portal Built for Laptops and Smartphones
}

\author{
Fazillah Mohmad Kamal ${ }^{1}$, Emmanuel O.C. Mkpojiogu ${ }^{2}$, Azham Hussain ${ }^{3}$, Emelda I. Emmanuel ${ }^{4}$ \\ ${ }^{1}$ School of Quantitative Sciences, Universiti Utara Malaysia, 06010 UUM, Sintok, Malaysia, \\ fazillah@uum.edu.my \\ ${ }^{2}$ School of Computing, Universiti Utara Malaysia, 06010 UUM, Sintok, Malaysia; \\ Department of Computer and Information Technology, Veritas University, Abuja, Nigeria, \\ ${ }^{3}$ School of Computing, Universiti Utara Malaysia, 06010 UUM, Sintok, Malaysia, \\ ${ }^{4}$ Department of Sociology, Ibrahim Badamasi Babangida University, Lapai, Nigeria.
}

\begin{abstract}
Designing software systems without considering the usability of such systems is tantamount to designing a poor quality product. There is the need to assess the usability of software systems under development (formative usability) and the already built software systems (summative usability). Formative usability helps in eliciting issues and problems inherent in the interface of such systems while summative usability is necessary for benchmarking in addition to post development problem elicitation. In this study, a formative usability was carried out on an online health sensitization portal built for both laptops and smartphones to capture usability issues and problems with their interfaces. The usability evaluation was conducted using moderated lab-

based usability testing method. The results revealed that though both the laptop and smartphone prototypes statistically had similar usability issues, the laptop prototype however, had greater amount of usability issues with greater criticality rates than was observed for the smartphone prototype. This calls for design attention to be given to both designs but particularly to the laptop design.
\end{abstract}

Keywords: Criticality rates, health sensitization portals, laptops, smartphones, usability problem frequencies

\section{INTRODUCTION}

Usability evaluation is about the last activities to be carried out in a software engineering process. Its aims are to ensure that the product developed is usable and satisfying to the users and to ensure that the users have good experience while interacting with it. It is geared toward ensuring design quality and improvement. A design that does not take into cognizance the intended users of the product may ultimately lead to users not being able to use it and eventually abandoning it to more usable alternatives, especially in a competitive environment. Design usability is the process of ensuring that a given design meets the usability needs of the users. It helps to reduce product rejection and increases product's productivity, success and survivability. Usability is usually defined within the context of the use of a product and the manner in which it is measured also reflects and defines that context (Brooke, 2013). ISO 9241-11 explains usability in terms of three quality attributes which are defined around the context of use. These attributes include: effectiveness that measures if users Actually finish their tasks and accomplish their objectives while using the given product. Next is efficiency that measures the extent to which users expend resources in achieving their goals while performing tasks in a given product and last is satisfaction that measures the level/ degree of comfort users experience in achieving their goals or while performing tasks in a given system (ISO 9241-11 Standard in Brooke, 2013; Brooke, 2010, Ghani et. al., 2019). The product where users are able to complete their tasks, but with the spending of large amount of time and effort and with unsatisfactory perceptions can be regarded as a product that is not usable. In addition, a product where users felt comfortable using but do not allow users to complete their tasks successfully and on which they expended a great deal of unproductive time and much effort can also be regarded as not being usable (Brooke, 2013; Sauro, 2011; Hussain, Mkpojiogu \& Kamal, 2016; Jadhar et al., 2013).

Users surf the Internet regularly in search of health related information. The Internet has become an information center for health matters and health seekers usually browse the content of the web to obtain useful tips that will inform or keep them informed on pertinent health issues. As these platforms receive regular visits, it is necessary to ensure that they are acceptable to users and comfortable to access and use by them. Information seekers get frustrated when they find it difficult to assess and use these health alerting or informing platforms. The difficulty of use puts a strain on users and makes them to dislike such platforms. The issues 
with these platforms could be information overload, poor navigation, broken links, complexities, unattractive interfaces and color confusions, poor understandability, poor learnability, poor readability. poor lucidity, inflexibility, irrelevant or incoherent content among others. Due to these issues, it is vital to factor in usability into the design of such platforms to enhance use, interaction, patronage, loyalty and positive word-of-mouth promotion, etc. To ascertain the usability of such platforms, formative usability are conducted during development and summative usability are done after the platforms are deployed to assess the issues incumbent on the platforms for immediate or future improvements to enhance the usability quality of the products (Culjak, 2012; Fox, 2005; Freudenheim, 2011; Grabenbauer, Fruhling, \& Windle, 2014; Ji, Chun \& Geller, 2013; Samuel, \& Zaiane, 2011; Hussein et al., 2019; Hussain et al., 2019).

There are several methods for evaluating the usability of an interface design. The commonly used usability method as reported in Jadhar et al (2013) are: user testing, think aloud, cognitive walkthrough, GOMS analysis, heuristic evaluation, software guidelines and field study (Jadhav et al, 2013; Grabenbauer et al, 2014). Cognitive walkthrough method explores the effect of design decisions on problem solving processes of users along with the ability of users to learn to use a system by exploration. This is usually done by experts that act as proxy users. The early use of this method was summative, and it is used toward the end of the design phase with developers as proxy users. In recent times, the technique is used formatively with the intended end-users used as evaluators for the prototype. Feedbacks are gotten from the intended users during the evaluation (Grabenbauer et al, 2014), however, with cognitive walkthrough, a potential bias is introduced in the selection of tasks which ultimately do not represent the work of the user, thus making the problem solving process of the user to be incompletely understood (Grabenbauer et al, 2014). In think aloud method, participants involved in the evaluation are asked to speak out their thoughts and verbally explain what they are thinking in the process of their carrying out their task scenarios. This is helpful as it releases and captures the mental model of users (Grabenbauer et al, 2014). The limitation of this method is that it is grossly subjective and hardly stands alone; it is usually combined with other method(s). The user testing methods which can either be lab-based or field based is carried out with users as participants while the facilitators observe and captures needed metrics. Heuristic evaluation employs experts who use a set of guidelines in evaluating a piece of software product (Hussain \& Mkpojiogu, 2017; Hussain et al., 2016; 2017).

Prior studies have concentrated in capturing usability metrics such as completion rates, time on tasks, error rates, conversion rates, efforts, and learning time, etc., however, these studies seldom elicit usability issues or practical problems with an interface and their associated criticality rates. This makes improvement efforts to be challenging. This study notwithstanding, seeks to assess software design by eliciting the problem frequencies and criticality/severity rates of an online health sensitization portal that is built for laptops and smartphone devices.

\section{METHODOLOGY}

This study was conducted in Universiti Utara Malaysia (UUM). In the study, a moderated The process of usability testing was used to assess usability of a health sensitization portal on both laptops and smartphones. A related subject design was utilized in the usability testing for laptops and smartphones. For laptop testing, a sample size of 20 with an estimated 20 percent margin of error at a 95 percent confidence level was used. Furthermore, a sample size of 9 At the 95 percent confidence mark, the expected 27 percent margin of error was used for smartphone testing.

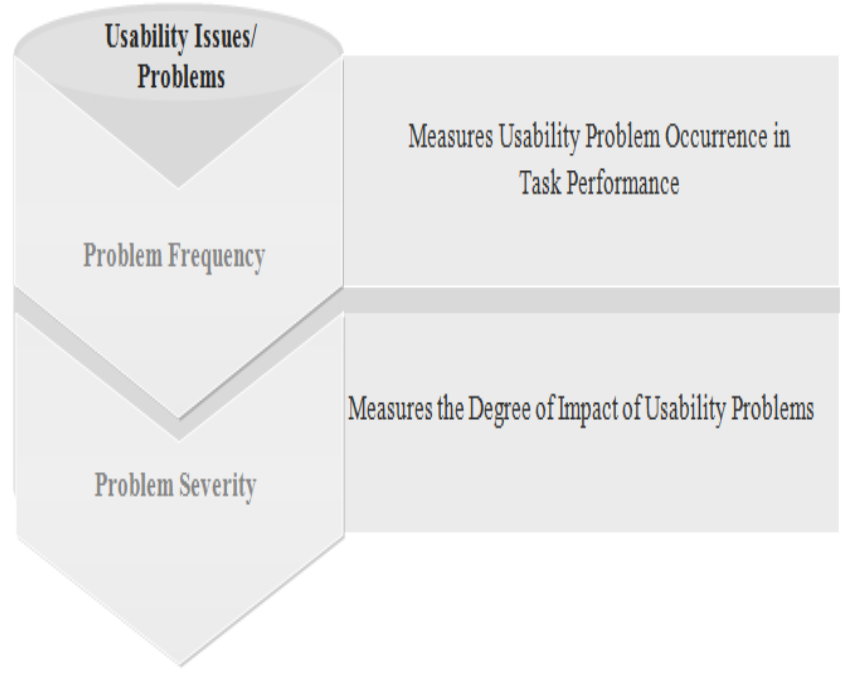

Figure 1: Research Metrics

The following two metrics were collected in the usability testing: problem frequency, and problem severity. These metrics are explained as follows (Figure 1):

Problem Frequency: This metric is the count of usability issues/problems observed during a usability evaluation. They may also be obtained from users during the post evaluation interviews. It measures problem occurrence in task performance.

Problem Severity: This metric is used to show the degree of impact a usability issue/ problem has on the usability of an interface and on the user experience of the system. In this study, the metric was measured with a 3-point rating scale as follows: i) Minor: This problem Some delay or minor annoyance is caused; ii) Moderate: This issue causes occasional failure of the task; for some users; causes delays and moderate irritation; iii) Critical: This problem leads to task failure. The problem causes user extreme irritation. In addition to this scale, the observations or ideas that users mention during the test or in the post evaluation interviews are also categorized as either an insight, suggestion or positive. 
Fazillah Mohmad Kamal et al., International Journal of Emerging Trends in Engineering Research, 8(10), October 2020, 6783-6787

The test protocol for the testing is as follows:

- System setup\& Internet connection

- In-briefing

- Pre-test questionnaire

- Test session (about 45 minutes)

- Post-test questionnaire

- Debriefing

\section{RESULTS}

The two metrics collected produced the following results:

\section{Problem Frequency}

This metrics measures the rate of occurrence of observed issues on the devices tested. The similar application ran on different devices, that is, on laptops and smartphones. The interfaces of laptops and smartphones have dissimilar characteristics. Tables 1 and 2 and Figure 2 provide details.

Table 1: Problem Frequency for Laptop

\begin{tabular}{|l|l|l|l|l|l|l|l|l|}
\hline Problem & P1 & P2 & P3 & P4 & P5 & P6 & P7 & P8 \\
\hline Frequency & 1 & 1 & 1 & 1 & 7 & 12 & 4 & 1 \\
\hline Total Users & 20 & 20 & 20 & 20 & 20 & 20 & 20 & 20 \\
\hline Proportion & 0.05 & 0.05 & 0.05 & 0.05 & 0.35 & 0.60 & 0.20 & 0.05 \\
\hline
\end{tabular}

Average Problem Frequency: 0.18 (18\%); Adjusted Average Problem Frequency: 0.12 (12\%)

Table 2: Problem Frequency for Smartphone

\begin{tabular}{|l|l|l|l|l|l|l|l|}
\hline Problem & P1 & P2 & P3 & P4 & P5 & P6 & P7 \\
\hline Frequency & 1 & 1 & 1 & 2 & 4 & 1 & 1 \\
\hline Total Users & 9 & 9 & 9 & 9 & 9 & 9 & 9 \\
\hline Proportion & 0.11 & 0.11 & 0.11 & 0.22 & 0.44 & 0.11 & 0.11 \\
\hline
\end{tabular}

Average Problem Frequency: 0.13 (13\%); Adjusted Average Problem Frequency: 0.08 (8\%)

The two tables above reveal the The frequency of issues with laptops and mobile interfaces. On average, for notebooks, both the problem frequency and the modified problem frequency are higher than for smart phones. An average adjusted issue frequency of 0.12 and 0.08 suggests that laptop and smartphone users have experienced an average of at least .12 and .08 laptop and smartphone issues, respectively. This illustrates that the online health sensitization platform offers mobile users a greater user experience than laptop users.

However, there is no substantial difference between the laptop and smartphone interfaces' average issue frequency, as follows: difference: (5 percent); P> 0.05; X2(1) = 0.042; 95 percent CI: -35 to 322 . The same applies to the average modified frequency of the problem: difference: $(4 \%)$, $\mathrm{P}>0.05$; X2(1)=0.106; CI 95 percent:-34 to 28 . This finding suggests that users have faced similar problems at a trust level of 95 percent on both laptop and mobile interfaces.

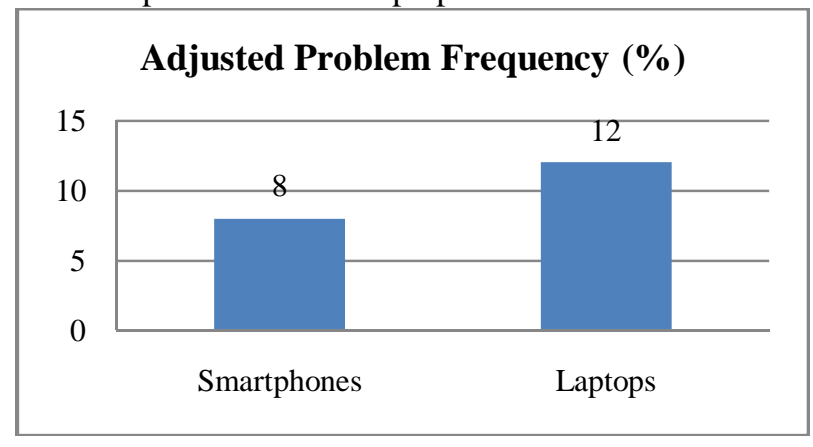

Figure 2: Adjusted Problem Frequency for Smartphones and Laptops

\section{Criticality Rate}

This metrics measures the level of seriousness and impact of each of the observed usability problems in the test. While some of the problems could be minor, that is, they cause some hesitation or slight irritation; some may be moderate, that is, they cause For some users, sometimes task failure; cause delays and mild annoyance; and some may be serious, that is, they contribute to task failure and cause users severe irritation. Nonetheless, in evaluating the criticality rate, only the critical or fatal problems are issues/problems are examined and analyzed.

Table 3: Laptop criticality rate

\begin{tabular}{|l|l|l|l|l|}
\hline Problem & P1 & P4 & P5 & P8 \\
\hline Frequency & 1 & 1 & 7 & 1 \\
\hline Total Users & 20 & 20 & 20 & 20 \\
\hline Proportion & 0.05 & 0.05 & 0.35 & 0.05 \\
\hline
\end{tabular}

Laptop Criticality Rate: 0.50 (50\%).

Table 4: Smartphone criticality rate

\begin{tabular}{|l|l|l|l|}
\hline Problem & P1 & P4 & P7 \\
\hline Frequency & 1 & 2 & 1 \\
\hline Total Users & 9 & 9 & 9 \\
\hline Proportion & 0.11 & 0.22 & 0.11 \\
\hline
\end{tabular}

Smartphone Criticality Rate: 0.44 (44\%)

Critical issues are those issues that users experience that lead to task failure and cause extreme frustration for users. These crucial issues were listed by an independent evaluator among 
the issues faced by users. From the study given, laptop users faced more serious problems than users of smart phones. The $6 \%$ difference between laptop and smartphone observed, however, did not vary from zero $(\mathrm{P}>0.05 ; \mathrm{X} 2(1)=0.011$; CI: 34 to 44$)$. This means the critical rate is statistically the same for the two types of devices.

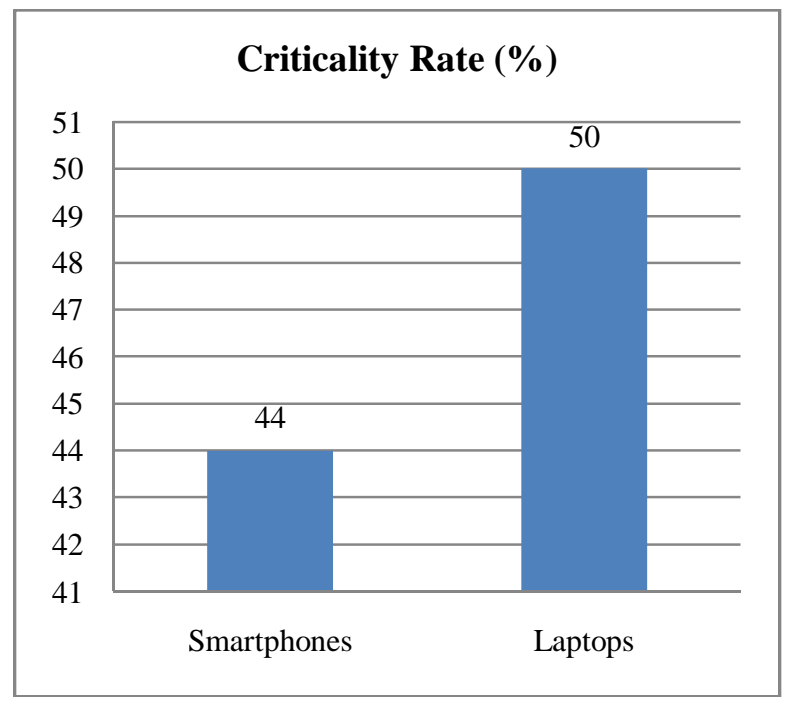

Figure 3: Criticality Rate for Smartphones and Laptops

\section{CONCLUSION}

The design of software products that is devoid of usability quality considerations is tantamount to the designing of poor quality product. For this cause, it is needful to assess the usability of software products under development (in terms of, formative usability) and the usability of already built software products (that is., summative usability). While formative usability enables the elicitation of issues and problems inherent in the interface of software products, summative usability is useful for benchmarking in addition to the usual elicitation of usability issues. In this study, a formative usability was conducted on an online health sensitization portal built to run on both laptops and smartphones to capture usability issues and problems on these interfaces. The usability evaluation was done using a moderated lab-based usability testing method. The results found that though both the laptop and smartphone prototypes statistically had the same usability issues, the laptop prototype however, had greater amount of usability issues with greater criticality rates when compared to those of the smartphone prototype. This calls for design attention to be given to both designs but specifically to the laptop design.

\section{REFERENCES}

[1] Brooke, J. (2013). SUS: A retrospective. Journal of Usability Studies, Vol. 8, Issue 2, February, pp. 29-40

[2] Brooks Jr., F. P. (2010). The Design of Designs: Essays from a Computer Scientist, Addison-Wesley.
[3] Culjak. G. (2012). Access, Awareness and Use of Internet Self-Help Websites for Depression in University Students, HICSS'12, Maui, HI, 4-7 Jan 2012, pp. 2655-2664

[4] Fox, S. (2005). Health Information Online. Pew Internet and American Life Project. http://www.pewinternet.org/PPF/r/156/report_display.as p. Accessed on 03/18/2015

[5] Freudenheim, M. (2011). Health Care is high among Web Searches. Pew Internet and American Life Project.http://www.pewinternet.org/MediaMentions/2011/NYT-health-Care-Is-High-Among-WebSearches.aspx. 2011, Accessed on March 18, 2015.

[6] Ghani, A.B.A., Kaliappen, N., Jermsittiparsert, K. (2019). Enhancing Malaysian SME Employee Work Engagement: The Mediating Role Of Job Crafting In The Presence Of Task Complexity, Self-Efficacy And Autonomy. International Journal of Innovation, Creativity and Change, 6 (11), pp. 1-18.

[7] Hussain, A., Mkpojiogu, E.O.C., \& Kamal, F.M. (2016). A systematic review on usability evaluation methods in m-commerce apps. Telecommunication, Electronic \& Computer Engineering (JTEC). 8(10), 29-34

[8] Hussein, I., Hussain, A., Mkpojiogu, E.O.C., \& Nathan, S.S. (2019). The state of user experience design practice in Malaysia. International Journal of Innovative Technology and Exploring Engineering, 8(8S), 491-497.

[9] Hussain, A., Hussein, I., Mkpojiogu, E.O.C., \& Sarlan, A. (2019). The state of user experience design (UXD) practice in Malaysia: an in-situ interview approach. International Journal of Innovative Technology and Exploring Engineering, 8(8S), 498-505.

[10] Hussain, A., \& Mkpojiogu, E.O.C. (2017). Predicting the perceived worth of software products requirements with customer satisfaction. Advanced Science Letters. 23(5), 4269-4273.

[11]Hussain, A., Mkpojiogu, E.O.C., \& Nawi, M.N.M. (2017). Capturing customer satisfaction and dissatisfaction in software requirements elicitation for features in proposed software systems. Journal of Engineering and Applied Sciences (JEAS), 12(21), 5590-5597

[12] Hussain, A., Mkpojiogu, E.O.C. \& Yusof, M.M (2016). Perceived usefulness, perceived ease of use, and perceived enjoyment as drivers for the user acceptance of interactive mobile maps. Proceedings of the $1^{\text {st }}$ International Conference on Applied Science and Technology (ICAST'16), Kedah, Malaysia. AIP Conf. $\begin{array}{lll}\text { Proc. } & 1761 & \text { (1). }\end{array}$ http://dx.doi.org/10.1063/1.4960891.

[13] Grabenbauer, L. A., Fruhling, A. L., \& Windle, J. R. (2014). Towards a cardiology/HER interaction workflow usability evaluation method. $201424^{\text {th }}$ Hawaii International Conference on System Science, Waikoloa, HI, IEEE, 6-9 Jan 2014, pp. 2626-2635. doi: 1109/HICSS.2014.331.

[14] Jadhar, D. J., Bhuthar, G., \& Mahta, V. (2013). Usability evaluation of messenger applications for android phones 
Fazillah Mohmad Kamal et al., International Journal of Emerging Trends in Engineering Research, 8(10), October 2020, 6783-6787

using cognitive walkthrough. APCHI'13: Proceedings of the $11^{\text {th }}$ Asia Pacific Conference on Computer-Human Interaction, September 24-27 2013, Bangalore, India, ACM. http://dx.doi.org/10.1145.2525194.2525202

[15] Ji, X., Chun, S.A. \& Geller, J. (2013). Social Infobuttons: Integrating Open Health Data with Social Data using Semantic Technology, Proc.SWIM'13, New York, USA, June 23, 2013.

[16] Samuel, H.W. \& Zaiane, O.R. (2011). Proc. HCMS: Conceptual Description of a Health Concept Management System, SEHC'11, Waikiki, HI, May 2223, 2011, pp.17-23.

[17] Sauro, J. (2011). A Practical Guide to the System Usability Scale: Background, Benchmarks, \& Best Practices. Denver, CO: Measuring Usability LLC. 